\title{
The severe complication of Stevens-Johnson syndrome induced by long-term clozapine treatment in a male schizophrenia patient: a case report
}

\author{
This article was published in the following Dove Press journal: \\ Neuropsychiatric Disease and Treatment \\ 9 April 2015 \\ Number of times this article has been viewed
}

\author{
Ming-Kung $\mathrm{Wu}^{\prime}$ \\ Weilun Chung ${ }^{2}$ \\ Ching-Kuan $\mathrm{Wu}^{2}$ \\ Ping-Tao Tseng ${ }^{2}$ \\ 'Kaohsiung Chang Gung Memorial \\ Hospital and Chang Gung University \\ College of Medicine, Kaohsiung, \\ Taiwan; ${ }^{2}$ Department of Psychiatry, \\ Tsyr-Huey Mental Hospital, Kaohsiung \\ Jen-Ai's Home, Kaohsiung, Taiwan
}

\begin{abstract}
Introduction: Stevens-Johnson syndrome (SJS) is a severe adverse drug reaction that can result in disability and mortality. SJS is defined as having a widespread distribution throughout the whole body surface area with $<10 \%$ extent of skin detachment and skin lesions. Some drugs, such as carbamazepine, have been reported to have a greater correlation to SJS. Although clozapine use has been mentioned as a risk factor for development of SJS, no report has clearly described the features of SJS as a reaction to clozapine use. Herein, we report the case of a patient presenting SJS after long-term clozapine treatment.

Case report: $\mathrm{Mr}$ A was a 54-year-old male with a diagnosis of chronic schizophrenia. He was hospitalized in a mental institute and received clozapine $200 \mathrm{mg} /$ day for 2 years, without discomfort or drug side effects. He developed acute-onset mouth edema, multiple oral and ocular ulcers, oral and ocular mucosa swelling, and multiple erythematous skin rashes over his entire body and extremities with hypertension and high fever. SJS was diagnosed after referral to a general hospital.

Results: The SJS subsided under supportive treatment.

Conclusion: Accumulated lymphocytes and macrophages in the epidermis and elevated TNF- $\alpha$ might cause an immune reaction and apoptosis and result in the clinical presentation of SJS. Clozapine is believed to modulate the immunologic reaction, and therefore might induce SJS through immunomodulation. This case highlights the importance of considering the possibility of SJS resulting from the use of drugs for which there are no reports of such a severe complication.
\end{abstract}

Keywords: psychiatry, side effect, pharmacotherapy, adverse reaction, pharmacy

\section{Introduction}

There have been many reports and articles discussing skin eruptions due to different classes of medication. ${ }^{1-4}$ These reactions result in different presentations, based on severity, from the simplest urticaria to the most severe reaction, Stevens-Johnson syndrome (SJS). ${ }^{5}$ SJS is a rare but severe adverse drug reaction with a cutaneous presentation, and can progress rapidly and even result in disability and mortality. ${ }^{6,7}$ SJS is considered to be a spectrum disease, a group that consists of SJS, erythema multiforme, and toxic epidermal necrolysis. ${ }^{8}$ In a report by Roujeau, SJS was defined as having a widespread distribution with $<10 \%$ extent of skin detachment and skin lesions including macules, blisters, flat atypical targets, and mucosal lesions. ${ }^{8}$ It also consists of some nonspecific symptoms and signs, such as occasional high fever, 
arthralgia, and general weakness. When affected, patients enter the most severe phase rapidly and may develop severe complications, such as septic shock. ${ }^{9}$ Mortality ranges widely according to different studies. ${ }^{5,10}$ The etiology of SJS is unclear and idiosyncratic. Some drugs, such as carbamazepine and phenytoin, have been reported to have a greater correlation to SJS than others. ${ }^{9}$

Clozapine is one of the most widely used atypical antipsychotics in current clinical practice. Despite its excellent effect on refractory psychosis, it has numerous side effect profiles, ${ }^{11}$ which include leukocytosis, hypersalivation, sedation, pneumonia, electrolyte imbalance, seizure, agranulocytosis, and its most severe complication, neuroleptic malignant syndrome. Although clozapine has been mentioned as a risk factor for the development of SJS, ${ }^{12}$ there is no report clearly describing the features of SJS in patients with clozapine use. Herein, we report the case of a patient presenting SJS after long-term clozapine treatment.

\section{Case report}

Mr A was a 54-year-old male who had been diagnosed as having chronic schizophrenia, paranoid type. The initial presentation of his psychosis consisted of auditory hallucination and delusions of persecution. He was hospitalized in the chronic ward of a mental institute. He had no previous physical illness history. The baseline laboratory data when hospitalized revealed no significant abnormality, and the routine chest X-ray and electrocardiography showed no significant finding. He had received clozapine $200 \mathrm{mg}$ /day for 2 years without discomfort or drug side effects. Two weeks before the event of SJS, he developed acute gastroenteritis with nausea and vomiting, and recovered from it spontaneously. However, he developed an acute onset of mouth edema, oral and ocular multiple ulcers, injected oral and ocular mucosa, and multiple erythematous skin rashes over his entire body and extremities. When the event of SJS came, he only took clozapine $200 \mathrm{mg}$ daily without any other concomitant drugs. His vital signs revealed hypertension, $153 / 101$, with a high fever of $39.1^{\circ} \mathrm{C}$. Because of the emergent condition, he was soon referred to a general hospital for intensive care, where SJS was diagnosed. The laboratory data at that time revealed acute inflammation with elevated $\mathrm{C}$-reactive protein $(143.2 \mathrm{mg} / \mathrm{L})$ and leukocytosis $\left(1.47 \times 10^{4} / \mu \mathrm{L}\right)$. There was not any acute renal or hepatic failure noted. After supportive treatment, his critical condition subsided and he returned to our hospital 1 month later. The follow-up laboratory data 1 month later revealed gradually improved leukocytosis. His psychotic symptoms were well controlled under risperidone $3 \mathrm{mg} /$ day, which was prescribed after this event subsided.
He did not have any obvious drug side effects under risperidone treatment.

\section{Results}

To the best of our knowledge, this is the first report to describe in detail the whole course of SJS in a patient with long-term clozapine use. Our patient fulfilled most of the diagnostic criteria of SJS found in different reports. ${ }^{7,8}$ Besides, according to the Naranjo algorithm, the probability of adverse drug reactions by clozapine is highly probable, with a score of $6 .{ }^{13}$ He recovered smoothly under supportive treatment, and had no sequelae.

\section{Conclusion}

The etiology of SJS is still unclear. Some researchers have focused on the relationship between HLA-B*1502 and SJS with carbamazepine use. ${ }^{14}$ However, this finding could be replicated only in Han Chinese subjects receiving carbamazepine; in Japanese and Korean subjects receiving carbamazepine, different HLA-B families are found to be related to SJS. ${ }^{15,16}$ At the present time, most published reports are focused on the relationship between HLA-B families and antiepileptic drugs only. ${ }^{17,18}$ Although some reports suggest that genetic screening techniques should be devised to screen for the risk of SJS before prescribing such drugs for patients with either epilepsy ${ }^{19,20}$ or mood disorder, ${ }^{21}$ another report has tried to investigate the implication of this pharmacogenetics technique in terms of other drugs, but this seems not implacable to be promoted to other drugs at the present time. ${ }^{22}$

However, the pathologic mechanism of SJS is still poorly established. In pathological reports, accumulated $\mathrm{CD}^{8+}$ $\mathrm{T}$ lymphocytes and macrophages (eg, Langerhans cells) in the epidermis ${ }^{23,24}$ and TNF- $\alpha$ elevated by macrophages ${ }^{25}$ might cause a cytotoxic cellular immune reaction and apoptosis in the epidermis and result in the clinical presentation of SJS. ${ }^{9}$ Clozapine actually is believed to elevate plasma TNF- $\alpha$ levels. ${ }^{26,27}$ Besides, in another report, clozapine revealed its ability to modulate the immunologic reaction, including that of IL-1 $\beta$, IL-8, monocyte chemotactic protein (MCP-1), and NF-кB1. ${ }^{28}$ Therefore, clozapine might, at least partially, induce SJS through its potential ability of immunomodulation. However, we still need direct study to prove this hypothesis.

This case highlights the importance of monitoring and considering the possibility of SJS as a reaction to drugs for which there are no previous reports of such severe complications. 


\section{Author contributions}

All authors contributed toward data analysis, drafting and revising the paper and agree to be accountable for all aspects of the work.

\section{Disclosure}

The authors report no conflicts of interest in this work.

\section{References}

1. Ahronowitz I, Fox L. Severe drug-induced dermatoses. Semin Cutan Med Surg. 2014;33(1):49-58.

2. Mockenhaupt M. Stevens-Johnson syndrome and toxic epidermal necrolysis: clinical patterns, diagnostic considerations, etiology, and therapeutic management. Semin Cutan Med Surg. 2014;33(1):10-16.

3. Sukasem C, Puangpetch A, Medhasi S, Tassaneeyakul W. Pharmacogenomics of drug-induced hypersensitivity reactions: challenges, opportunities and clinical implementation. Asian Pac J Allergy Immunol. 2014;32(2):111-123.

4. Filotico R, Mastrandrea V. Cutaneous targets in drug-induced reactions. G Ital Dermatol Venereol. 2014;149(2):227-235.

5. Roujeau JC, Stern RS. Severe adverse cutaneous reactions to drugs. N Engl J Med. 1994;331(19):1272-1285.

6. Wolff K, Johnson RA, Saavedra AP. Fitzpatrick's Color Atlas and Synopsis of Clinical Dermatology. 7th ed. New York: McGraw-Hill Medical; 2013.

7. Letko E, Papaliodis DN, Papaliodis GN, Daoud YJ, Ahmed AR, Foster CS. Stevens-Johnson syndrome and toxic epidermal necrolysis: a review of the literature. Ann Allergy Asthma Immunol. 2005;94(4): 419-436; quiz 436-438, 456.

8. Roujeau JC. The spectrum of Stevens-Johnson syndrome and toxic epidermal necrolysis: a clinical classification. J Invest Dermatol. 1994;102(6):28S-30S.

9. Fritsch PO, Sidoroff A. Drug-induced Stevens-Johnson syndrome/toxic epidermal necrolysis. Am J Clin Dermatol. 2000;1(6):349-360.

10. Weinand $\mathrm{C}, \mathrm{Xu} \mathrm{W}$, Perbix W, et al. 27 years of a single burn centre experience with Stevens-Johnson syndrome and toxic epidermal necrolysis: analysis of mortality risk for causative agents. Burns. 2013;39(7): 1449-1455.

11. Stanniland C, Taylor D. Tolerability of atypical antipsychotics. Drug Saf. 2000;22(3):195-214.

12. Physicians' Desk Reference: 66th ed. Oradell, NJ: Medical Economics Co.; 2011.

13. Naranjo CA, Busto U, Sellers EM, et al. A method for estimating the probability of adverse drug reactions. Clin Pharmacol Ther. 1981;30(2): 239-245.

14. Chung WH, Hung SI, Hong HS, et al. Medical genetics: a marker for Stevens-Johnson syndrome. Nature. 2004;428(6982):486.
15. Kaniwa N, Saito Y, Aihara M, et al; JSAR research group. HLAB*1511 is a risk factor for carbamazepine-induced Stevens-Johnson syndrome and toxic epidermal necrolysis in Japanese patients. Epilepsia. 2010;51(12):2461-2465.

16. Kim SH, Lee KW, Song WJ, et al; Adverse Drug Reaction Research Group in Korea. Carbamazepine-induced severe cutaneous adverse reactions and HLA genotypes in Koreans. Epilepsy Res. 2011;97(1-2): 190-197.

17. Li X, Yu K, Mei S, et al. HLA-B*1502 increases the risk of phenytoin or lamotrigine induced Stevens-Johnson syndrome/toxic epidermal necrolysis: evidence from a meta-analysis of nine case-control studies. Drug Res (Stuttg). 2015;65(2):107-111.

18. Sun D, Yu CH, Liu ZS, et al. Association of HLA-B*1502 and *1511 allele with antiepileptic drug-induced Stevens-Johnson syndrome in central China. J Huazhong Univ Sci Technolog Med Sci. 2014;34(1): $146-150$.

19. Dong D, Sung C, Finkelstein EA. Cost-effectiveness of HLA-B*1502 genotyping in adult patients with newly diagnosed epilepsy in Singapore. Neurology. 2012;79(12):1259-1267.

20. Hassan I. HLA-B*1502 screening in carbamazepine and lamotrigine candidates of Asian background. Aust N Z J Psychiatry. 2012;46(11): 1106-1107.

21. Laje G. Pharmacogenetics of mood disorders: what clinicians need to know. CNS Spectr. 2013;18(5):272-284.

22. Neuman MG, Cohen L, Nanau RM, Hwang PA. Genetic and immune predictors for hypersensitivity syndrome to antiepileptic drugs. Transl Res. 2012;159(5):397-406.

23. Correia O, Delgado L, Ramos JP, Resende C, Torrinha JA. Cutaneous $\mathrm{T}$-cell recruitment in toxic epidermal necrolysis. Further evidence of $\mathrm{CD}^{8+}$ lymphocyte involvement. Arch Dermatol. 1993;129(4): 466-468.

24. Villada G, Roujeau JC, Clérici T, Bourgault I, Revuz J. Immunopathology of toxic epidermal necrolysis. Keratinocytes, HLA-DR expression, Langerhans cells, and mononuclear cells: an immunopathologic study of five cases. Arch Dermatol. 1992;128(1):50-53.

25. Paquet P, Nikkels A, Arrese JE, Vanderkelen A, Piérard GE. Macrophages and tumor necrosis factor alpha in toxic epidermal necrolysis. Arch Dermatol. 1994;130(5):605-608.

26. Lett TA, Wallace TJ, Chowdhury NI, Tiwari AK, Kennedy JL, Müller DJ. Pharmacogenetics of antipsychotic-induced weight gain: review and clinical implications. Mol Psychiatry. 2012;17(3):242-266.

27. Røge R, Moller BK, Andersen CR, Correll CU, Nielsen J. Immunomodulatory effects of clozapine and their clinical implications: what have we learned so far? Schizophr Res. 2012;140(1-3):204-213.

28. Sárvári AK, Veréb Z, Uray IP, Fésüs L, Balajthy Z. Atypical antipsychotics induce both proinflammatory and adipogenic gene expression in human adipocytes in vitro. Biochem Biophys Res Commun. 2014; 450(4):1383-1389.
Neuropsychiatric Disease and Treatment

\section{Publish your work in this journal}

Neuropsychiatric Disease and Treatment is an international, peerreviewed journal of clinical therapeutics and pharmacology focusing on concise rapid reporting of clinical or pre-clinical studies on a range of neuropsychiatric and neurological disorders. This journal is indexed on PubMed Central, the 'PsycINFO' database and CAS,

\section{Dovepress}

and is the official journal of The International Neuropsychiatric Association (INA). The manuscript management system is completely online and includes a very quick and fair peer-review system, which is all easy to use. Visit http://www.dovepress.com/testimonials.php to read real quotes from published authors. 